\title{
PENGARUH HEDONIC SHOPPING VALUE DAN STORE ATMOSPHERE TERHADAP IMPULSIVE BUYING PADA KONSUMEN CARREFOUR DI PONTIANAK
}

\author{
Diana Fitriani \\ STMIK Pontianak; Jl. Merdeka No. 372 Pontianak, 0561-735555 \\ Jurusan Sistem Informasi, STMIK Pontianak, Pontianak \\ e-mail: dianafitriani_8881@yahoo.com
}

Diterima: 4 Januari 2018/ Disetujui : 22 Januari 2018

\begin{abstract}
The main purpose of this research is to assess the effect of hedonic shopping value and store atmosphere to the impulsive buying of Carrefour consumen in Pontianak. Double analysis resgresion is the research method used with SPSS version 20.0. Ordinary least square analysis as valid assessment of research. Study research with descriptive analysis method applied. Hedonic shopping value $\left(X_{1}\right)$, store atmosphere $\left(X_{2}\right)$ is the independent variable, the dependent variabel that is impulsive buying (Y). Questioner as the instrument and research variabel consists of questioner using assessment method based on Silvera theory for independent variabel, otherwise the dependent variabel based on Rachmawati teory and likert scale as the assessment used. The population based on Disdukcapil data is 653.611,the number of respondents accepted is 100 people and accidental sampling as the sampling technique. Based on the partial research, then it is gained 31,92\% for store atmosphere variabel $\left(X_{2}\right)$ to impulsive buying, otherwise hedonic shopping value $\left(X_{1}\right)$ is $1,90 \%$. The simultaneous research gained is $59,2 \%$ for hedonic shopping value variabel $\left(X_{1}\right)$ and store atmosphere $\left(\mathrm{X}_{2}\right)$ effect positively. The result shows that store atmosphere at Carrefour Pontianak effect consumers in shopping his effect consumers in shopping his money more than hedonic shopping value.
\end{abstract}

Keywords : hedonic shopping value, store atmosphere, impulsive buying, deskriptif analysis

\begin{abstract}
ABSTRAK
Tujuan utama dari penelitian ini untuk menilai pengaruh hendonic shopping value dan store atmosphere terhadap impulsive buying pada konsumen Carrefour dipontianak. Metode penelitian menggunakan analisis regresi linier berganda dengan program spss versi 20.0. Analisis ordiary least square sebagai alat ukur kelayakan penelitian. Penelitian ini berupa studi kasus dengan metode penelitian deskriptif analisis. Hedonic shopping value (X1) dan store atmosphere (X2) adalah variable bebas, variabel terikatnya yaitu impulsive buying $(Y)$. Instrument dan variable penelitian berupa kuesioner yang berisi pertanyaan dengan menggunakan metode pengukuran berdasarkan teori dari Silvera untuk variabel bebas sedangkan variabel terikat berdasarkan teori dari Rachmawati. Skala pengukuran menggunakan skala likert. Jumlah populasi berdasarkan data Disdukcapil berjumlah 653.611, jumlah responden yang diambil berjumlah 100, teknik sampling menggunakan accidental sampling. Berdasarkan penelitian secara parsial diperoleh 31,92\% untuk variabel store atmosphere (X2) terhadap impulsive buying sedangkan hedonic shopping value (X1) sebesar 1,90\%. Penelitian secara simultan atau bersama-sama diperoleh 59,2\% bahwa variabel hedonic shopping value (X1) dan store atmosphere (X2) berpengaruh secara positif. Hasil tersebut menyatakan bahwa pada Carrefour Pontianak store atmosphere mempengaruhi konsumen dalam membelanjakan uangnya lebih besar disbanding hedonic shopping value.
\end{abstract}

Kata kunci-hedonic shopping value, store atmosphere, impulsive buying, deskriptif analisis 


\section{PENDAHULUAN}

Teknologi dan perkembangan jaman yang semakin moderen menyebabkan menjamurnya pasar bergaya moderen dengan konsep one stop shopping. Kota Pontianak sejak tahun 2000 telah memiliki pusat perbelanjaan modern . Kehadiran berbagai pasar modern di Pontianak tentu saja berdampak terhadap daya beli konsumen sehingga mendorong perusahaan untuk terus mempertahankan eksistensinya dalam memenuhi kebutuhan dan keinginan konsumen dalam membelanjakan uang.

Berdasarkan kebutuhan konsumen terhadap produk maka setiap perusahaan berlomba-lomba untuk berproduksi dengan berbagai macam alasan demi menarik minat konsumen. Perilaku konsumen yang cenderung berubah-ubah menciptakan kondisi pembelian menjadi impulsive buying. Seseorang melakukan impulsive buying bisa dipengaruhi oleh beberapa faktor yaitu hedonic shopping value, shopping lifestyle dan positive emotion [1].

Setiap kali konsumen mengalami impulsive buying salah satu pendorong terbesar adalah keinginan hedonis atau sebab lain diluar alasan ekonomi, seperti karena rasa senang, fantasi, sosial atau pengaruh emosional. Sehingga hedonic shopping value memainkan peran penting dalam proses pengambil keputusan dalam berbelanja. Pengaruh lain dirasa melalui store atmosphere atau kondisi toko dalam mendekorasi atribut belanja sehingga menarik minat konsumen untuk melakukan kegiatan belanja.

Sekarang ini pusat perbelanjaan dengan konsep one stop shopping semakin menjamur. Salah satunya adalah Carrefour. Berdiri sejak tahun 2010 bertempat di Matahari Mall. Perusahaan Carrefour merupakan hypermarket pertama yang dibuka diperancis pada tahun 1963. Pada tahun 1999 bergabung dengan Promodes Carrefour dan menjadi pemimpin bisnis ritel di Eropa dan merupakan perusahaan terbesar kedua di dunia. Selama 40 tahun Carrefour telah tumbuh menjadi salah satu terkemuka di dunia kelompok distribusi. Format yang diusung oleh perusahaan ini adalah hypermarket, supermarket, diskon dan kenyamanan.

Warga kota Pontianak adalah salah satu warga yang memiliki perilaku perilaku konsumtif. Berbelanja menjadi alat pemuas keinginan mereka akan produk produk yang sebenarnya tidak terlalu mereka butuhkan, akan tetapi karena pengaruh trend atau mode yang tengah berlaku maka konsumen merasa ingin melakukan pembelian bahkan merasa memiliki keharusan untuk melakukan pembelian. Faktor yang dianggap sebagai pendorong terbesar adalah segala hal yang berhubungan dengan kondisi tempat berbelanja dan atribut yang melekat pada produk tersebut.

Carrefour secara aktif berkomitmen untuk mempromosikan pembangunan ekonomi lokal. Karena kegiatan eceran semua tentang kontak dengan orang-orang, kelompok perekrutan lokal secara konsisten menekankan ditambah pelatihan manajemen dan staf pada pekerjaan dimana pun mereka bekerja.

Perilaku impulsive buying sering dipengaruhi oleh beberapa hal seperti hedonic shopping value dan store atmosphere. Pembelian impulsive merupakan kesenangan yang didorong pencapaian tujuan yang bersifat hendonik. Konsumsi yang bersifat hendonik dapat juga mencerminkan nilai pengalaman berbelanja seperti fantasi, arousal, stimulasi sensorik, kenikmatan, kesenangan, rasa ingin tahu dan hiburan [2]. Atribut toko memiliki faktor sosial yng dapat mempengaruhi pembelian yang tidak direncanakan, bantuan dari staff toko dianggap mampu merangsang proses pembelian impulsif. Perubahan yang dibuat pada design dari lingkungan pembelian yang menghasilkan efek-efek emosional khusus yang kemudian meningkatkan kemungkinan bahwa pembelian akan berlangsung [3].

Atmosphere toko menjadi salah satu faktor penentu dalam menentukan ekspektasi terhadap konsumen dalam membelanjakan uangnya. Atmosphere merupakan kunci dalam menarik dan membuat konsumen terkesan dengan pengalaman berbelanja didalam toko. Pada ilmu ritel 
memfokuskan pada cakupan penjualan dengan promosi. Hal tersebut sangat mempengaruhi keinginan untuk berbelanja.

Berdasarkan penelitian pendahulu dinyatakan bahwa yang masih berkaitan dengan ini menyatakan bahwa hedonic shopping value, positive emotion, Shopping lifestyle berpengaruh positif terhadap impulsive buying dinyatakan bahwa untuk meningkatkan nilai hedonic dari suatu pusat pembelajaan dengan adalah dengan menciptakan program promosi dengan hadiah yang menaik serta selalu memperbaharui dekorasi pada setiap corner sehingga pengunjuk akan semakin merasa nyaman dan memiliki pengalaman unik pada saat berbelanja [4]. penelitian lain yang masih berkaitan dengan ini menyatakan bahwa produk yang paling sering diakses responden adalah makanan, transportasi dan pakaian. Social media mempengaruhi tahap purchase decision dan post purchase pada keputusan pembelian [5].

Penelitian serupa berhasil memperoleh kesimpulan bahwa hedonic shopping value memiliki pengaruh yang paling besar kedua setelah positive emotion dibanding variable lain, informasi ini memperkuat bahwa besar kemungkinan orang melakukan aktivitas belanja karena faktor kesenangan dan kebanggaan [6]. Hasil lain yang masih mengenai variable yang sama menyatakan bahwa benar shop environment, staff integrated marketing communication dan hedonic shopping value berpengaruh terhadap impulsive buying secara positif dinyatakan bahwa dengan meningkatkan setiap elemen tersebut maka impulsive buying konsumen juga akan meningkat, dan hal lain yang paling berpengaruh dominan adalah hedonic shopping value [7]. Penelitian lain yang mengangkat mengenai variabel yang juga peneliti angkat menunjukkan bahwa store atmosphere dengan elemen-elemen seperti exterior facilities, general interior, store layout, display interior dan social dimensions berpengaruh positif dan signifikan terhadap respon emosional konsumen dalam melakukan aktifitas belanja mereka [8].

\section{METODE PENELITIAN}

Penelitian berbentuk studi kasus dan metode penelitian bersifat deskriptif analitis. Teknik pengumpulan data yang digunakan berupa wawancara, observasi dan penyebaran angket daftar pertanyaan kepada sejumlah responden berdasarkan teori yang menunjang penyelesaian masalah penelitian yaitu mengenai hedonic shopping value dan store atmosphere terhadap impulsive buying yang pernah melakukan pembelian di Carrefour, sehingga jawaban responden dapat dipertanggung jawabkan kebenarannya. Teknik penarikan sampel menggunakan teknik non probabilitas sampling yaitu accidental sampling dimana teknik sampel ini menyatakan bahwa siapa saja yang dijumpai pada saat penelitian berlangsung dapat dijadikan sebagai sampel dalam penelitian [9]. Total responden sebanyak 100 orang. Pengukuran menggunakan metode analisa regresi berganda dan didukung software SPSS 20.0 untuk melakukan olah data secara simultan dan parsial. Pengujian ini terdapat dua variabel pendukung yaitu hedonic shopping value $\left(\mathrm{X}_{1}\right)$, store atmosphere $\left(\mathrm{X}_{2}\right)$ dan impulsive buying (Y). Populasi dalam penelitian adalah masyarakat kota Pontianak sebanyak 653.611 jiwa [10].

Berdasarkan keterangan diatas maka untuk melihat pengaruh variabel bebas terhadap variabel terikat digunakan analisis regresi berganda menjadi suatu model empiris [9], dengan rumus sebagai berikut :

$$
Y=a+b_{1} X_{1}+b_{2} X_{2}+e
$$

Dimana :

$\mathbf{Y}=$ impulsive buying

$\mathbf{X}_{\mathbf{1}} \quad=$ hedonic shopping value

$\mathbf{X}_{2}=$ store atmoshere

$\mathbf{a}=$ Konstanta

b = Masing-masing adalah koefisien regresi variabel $\mathrm{X}$

$\mathbf{E}=$ Nilai signifikan $<0,05(\mathrm{P} \leq 0,05)$.

Stándar Error 
Hipótesis penelitian diuraikan untuk membantu penelitian dalam mencari jawaban yang paling memungkinkan dalam menyelesaikan kasus penelitian secara simultan maupun secara parsial. Bentuk hipótesis secara simultan adalah $\mathrm{H}_{0}$ diduga tidak ada pengaruh yang signifikan antara variabel $\mathrm{X}_{1}$ dan $\mathrm{X}_{2}$ secara simultan terhadap variabel $\mathrm{Y}$ sedangkan $\mathrm{H}_{\mathrm{a}}$ diduga ada pengaruh yang signifikan antara variabel $\mathrm{X}_{1}$ dan $\mathrm{X}_{2}$ secara simultan terhadap variabel $\mathrm{Y}$. Dasar pengambilan keputusan dilakukan dengan membandingkan antara nilai $F_{\text {hitung }}$ dengan $F_{\text {tabel }}$, jika $F_{\text {hitung }}>F_{\text {tabel }}$ maka $\mathrm{H}_{\mathrm{a}}$ diterima dan $\mathrm{H}_{\mathrm{o}}$ ditolak akan tetapi sebalinya jka $\mathrm{F}_{\text {hitung }}<\mathrm{F}_{\text {tabel }}$ maka $\mathrm{H}_{\mathrm{a}}$ ditolak dan $\mathrm{H}_{\mathrm{o}}$ diterima. Sedangkan pengajuan hipótesis secara parsial yaitu Ho diduga tidak ada pengaruh yang signifikan antara variabel $\mathrm{X}_{1}$ dan $\mathrm{X}_{2}$ secara parsial terhadap variabel $\mathrm{Y}$.

Bentuk hipotesis secara parsial berupa $\mathrm{H}_{\mathrm{o}}$ diduga tidak ada pengaruh yang signifikan antara $\mathrm{X}_{1}$ dan $\mathrm{X}_{2}$ secara parsial terhadap variabel $\mathrm{Y}$ sedangkan $\mathrm{H}_{\mathrm{a}}$ diduga ada pengaruh yang signifikan antara variabel $\mathrm{X}$ secara parsial terhadap $\mathrm{Y}$. Dasar pengambilan keputusan dilakukan dengan membandingkan antara nilai $t_{\text {hitung }}$ dengan $t_{\text {tabel }}$ yaitu jika $t_{\text {hitung }}>t_{\text {tabel }}$ maka $\mathrm{H}_{\mathrm{a}}$ diterima dan $\mathrm{H}_{\mathrm{o}}$ ditolak sedangkan jika $t_{\text {hitung }}<\mathrm{tt}_{\text {abel }}$ maka $\mathrm{H}_{\mathrm{a}}$ ditolak dan $\mathrm{H}_{\mathrm{o}}$ diterima.

Pengujian hipotesis dilakukan dengan melihat nilai signifikan hasil analisis regresi. Hipotesis dapat diterima jika nilai signifikan dari masing-masing variabel yang diuji memperlihatkan nilai yang lebih kecil dan sama dengan 0,05 ( $\mathrm{P} \leq 0,05 ; \alpha=5 \%$ ). Apabila nilai signifikan $\leq 0,05$, berarti hipotesis penelitian dapat diterima.

Penelitian mengarah pada model regresi linier berganda dan didukung dengan pengujian validitas dan reliabilias yang berguna untuk memastikan alat ukur adalah benar dan handal. Selain itu pengujian ini juga dianggap perlu untuk memasukkan pengujian asumsi klasik atau biasa dikenal dengan istilah OLS (Ordinary Least Square).

Uji validitas [9] syarat minimum suatu instrument dianggap valid jika nilai $\mathrm{r}$ (corrected item) $>0,3$ dan uji reliabilitas suatu instrument dapat dikatakan handal jika koefisien alpha mempunyai nilai lebih besar dari 0,60[9]. Uji asumsi klasik atau ordinary least square [9] terdiri dari uji normalitas yaitu bertujuan untuk menguji apakah dalam model regresi variabel bebas dan variabel terikat keduanya mempunyai distribusi normal atau tidak, dasar pengambilan keputusan dibagi dengan Standard Error Skewness atau nilai statistik kurtosis dibagi dengan Standard Error Kurtosis dimana jika skor hasil pembagian berada antara -2 dan 2 maka distribusi data dinyatakan normal. Deteksi multikolinieritas merupakan situasi dimana terjadi korelasi variabel bebas antara satu dengan yang lainnya, dapat dilihat dari nilai VIF berada dibawah 10, yaitu peneliti dapat melihatnya dari hasil Collinearity Statistic pada tabel Coefficients. Uji autokorelasi adalah prosedur pendeteksi terjadinya hubungan antara variabel bebas itu sendiri atau berkorelasi sendiri dengan dilihat pada tabel Durbin Watson. Deteksi heterokedastisitas bertujuan untuk menguji apakah dalam model regresi terjadi ketidaksamaan varians dari residual satu pengamatan kepengamatan yang lain. Nilai residual adalah selisih atau tingkat kesalahan antara nilai pengamatan dengan nilai prediksi. Dalam regresi salah satu asumsi yang harus dipenuhi adalah bahwa varians dari residual pengamatan satu ke pengamatan yang lain tidak memiliki pola tertentu. Pola yang tidak sama ditunjukkan dengan nilai yang tidak sama antar satu varians dalam residual, gejala varians yang tidak sama ini disebut dengan homokedastisitas. Terakhir adalah uji linieritas berguna untuk menguji hubungan antar variabel independen dan dependen agar linier, dapat dilihat melalui grafik linieritas.

Data yang diperoleh akan ditabulasi dengan skala likert. Penjabaran mengenai Skala likert yang digunakan untuk membantu menyelesaikan kasus dalam penelitian adalah umumnya digunakan untuk menilai pendapat atau persepsi responden mengenai perilaku dan fenomena sosial dalam 
penelitian. Kuesioner diajukan dengan menentukan skala lima tingkat yaitu, $1=$ sangat tidak setuju, 2 = tidak setuju, $3=$ kurang setuju, $4=$ setuju, $5=$ sangat setuju [8]. Skala ini merupaka skala ganjil yang berguna untuk memberikan pilihan jawaban terhadap setiap pertanyaan yang diberikan dalam kuesioner terhadap responden.

\section{HASIL DAN PEMBAHASAN}

Mengukur pengaruh hedonic shopping value terhadap impulsive buying pada konsumen Carrefour Pontianak mendatangkan keuntungan dan informasi penting bagi perusahaan dan peneliti. Perusahaan akan mendapatkan gambaran yang lebih akurat berdasarkan hasil survey yang peneliti lakukan selama waktu penelitian berjalan. Penyebaran kuesioner kepada konsumen yang berada dilokasi pada saat peneliti melakukan observasi kepada 100 responden. Kuesioner terdiri dari 26 item pertanyaan, 9 item untuk variabel hedonic shopping value, 11 item untuk variabel store atmosphere dan 6 item pertanyaan untuk variabel impulsive buying. Pada setiap item pertanyaan akan ditabulasi sehingga menghasilkan harapan yang diinginkan.

a. Uji Validitas

Suatu test atau instrumen pengukur alat agar dapat menjalankan fungsi ukur yang sesuai dengan maksud dilakukannya pengukuran tersebut. Syarat minimum suatu instrumen dianggap valid jika nilai $\mathrm{r}($ corrected item $)>0,3$. Hasil pengujian validitas terhadap semua variabel dalam penelitian ini dilihat pada table 1 :

Tabel 1 Hasil Uji Validitas Instrumen Penelitian

\section{Item-Total Statistics}

\begin{tabular}{|l|c|c|c|c|c|}
\hline & $\begin{array}{c}\text { Scale Mean if } \\
\text { Item Deleted }\end{array}$ & $\begin{array}{c}\text { Scale Variance } \\
\text { if Item Deleted }\end{array}$ & $\begin{array}{c}\text { Corrected } \\
\text { Item-Total } \\
\text { Correlation }\end{array}$ & $\begin{array}{c}\text { Squared } \\
\text { Multiple } \\
\text { Correlation }\end{array}$ & $\begin{array}{c}\text { Cronbach's } \\
\text { Alpha if Item } \\
\text { Deleted }\end{array}$ \\
\hline $\begin{array}{l}\text { Hedonic } \\
\text { Shopping } \\
\text { Value }\end{array}$ & 7,2864 &, 895 &, 734 &, 572 &, 864 \\
\hline $\begin{array}{l}\text { Store } \\
\text { Atmosphere }\end{array}$ & 7,1519 &, 970 &, 838 &, 703 &, 774 \\
\hline $\begin{array}{l}\text { Impulsive } \\
\text { Buying }\end{array}$ & 6,9141 &, 960 &, 740 &, 592 &, 851 \\
\hline
\end{tabular}

Berdasarkan hasil uji validitas pada table 1 nilai $\mathrm{r}$ (corrected item) $>0,3$ untuk semua variabel dalam penelitian ini. Dapat disimpulkan bahwa alat ukur penelitian ini adalah valid sehingga layak untuk digunakan sebagai instrumen penelitian. 
b. Uji Reliabilitas

Reliabilitas adalah indeks yang menunjukkan sejauh mana suatu alat pengukur dapat dipercaya atau dapat diandalkan. Pengujian reliabilitas dalam penelitian ini dilakukan dengan menggunakan melihat nilai Alpha Cronbach. Suatu instrumen dikatakan handal (reliabel) apabila koefisien alpha mempunyai nilai lebih besar dari 0,60 . Hasil pengujiann reliabilitas terhadap semua variabel dalam penelitian ini dapat dilihat pada tabel 2 :

Tabel 2 Reliability Statistics

\begin{tabular}{|c|c|c|}
\hline $\begin{array}{c}\text { Cronbach's } \\
\text { Alpha }\end{array}$ & $\begin{array}{c}\text { Cronbach's } \\
\text { Alpha Based } \\
\text { on } \\
\text { Standardized } \\
\text { Items }\end{array}$ & N of Items \\
\hline, 879 &, 883 & 3 \\
\hline
\end{tabular}

Berdasarkan hasil uji reliabilitas pada tabel 2 dinyatakan bahwa nilai alpha cronbach adalah 0,879 $>0,60$. Dapat disimpulkan bahwa alat ukur penelitian ini dapat dianggap andal (reliabel).

c. Uji Asumsi Klasik Ordinary Least Square (OLS)

1. Uji Normalitas

Uji normalitas merupakan suatu jenis uji statistik untuk menentukan apakah suatu populasi berdistribusi normal atau tidak. Normal atau tidaknya suatu data dapat dilihat dari posisi atau penyebaran titik data. Apabila titik tersebut berada disekitar garis dalam penelitian ini yaitu garis kepuasan kerja maak data tersebut berdistribusi normal. Seperti dilihat pada Gambar 1 :

Normal P-P Plot of Regression Standardized Residual

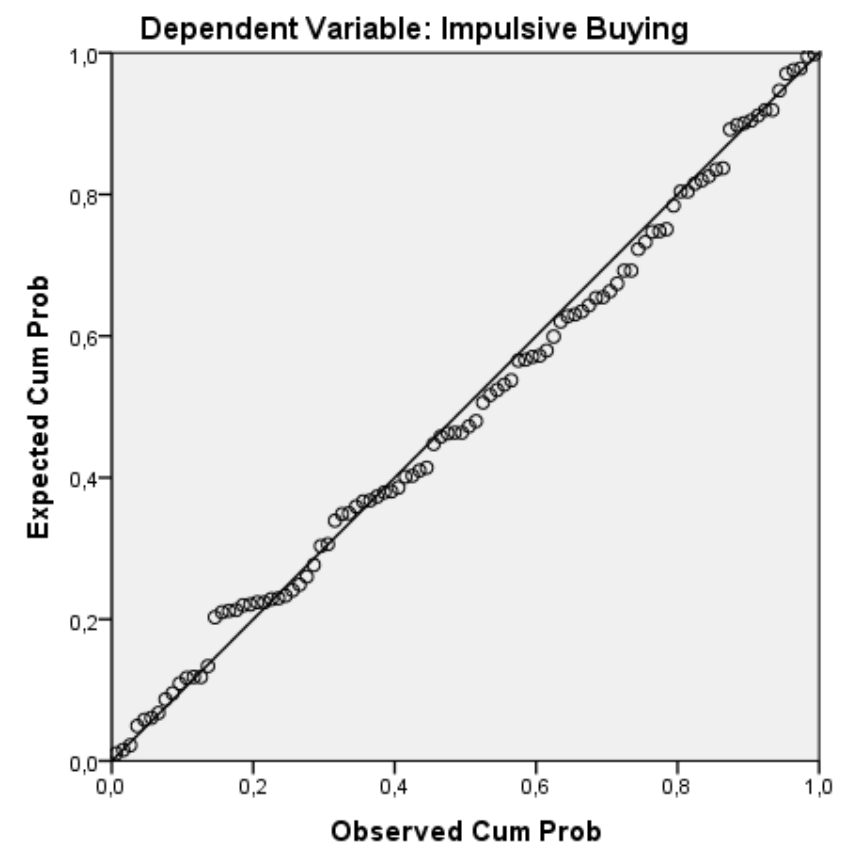

Gambar 1. Grafik Normalitas 
2. Uji Multikolinieritas

Agar model dapat dianalisis dan dapat memberikan hasil yang representatif, maka perlu diuji terhadap gejala multikolinieritas. Multikolinieritas adalah situasi dimana terjadi korelasi variabel-variabel bebas antara satu dengan yang lainnya. Untuk mengetahui ada atau tidaknya gejala multikolinieritas pada model regresi berganda yang diajukan, dapat dilihat melalui perhitungan Variance Inflating Factor (VIF). Nilai VIF dibawah 10 maka tidak terjadi multikolinieritas. Uji multikolinieritas dilihat pada tabel 3 :

Tabel 3 Hasil Pengujian Multikolinieritas

\begin{tabular}{|c|c|c|}
\hline Variabel & VIF & Keterangan \\
\hline X1 & 2.291 & Tidak terjadi \\
X2 & 2.291 & Multikolinieritas \\
\hline
\end{tabular}

Dapat disimpulkan bahawa variabel independen dalam penelitian ini terbebas dari gejala multikolinieritas. Karena nilai Variance Inflanting Factor (VIF) untuk variabel bebas nilainya kurang dari 10.

3. Uji Autokorelasi

Model dianalisis sehingga mampu memberikan hasil yang representative sehingga perlu diuji terhadap gejala autokorelasi. Autokorelasi adalah terjadinya hubungan antara variabelvariabel bebas itu sendiri atau berkorelasi sendiri. Prosedur pendeteksian masalah autokorelasi dapat digunakan pengujian Durbin Watson. Dalam pengujian ini diperoleh nilai Durbin Watson sebesar 2.558. Sesuai dengan tabel uji autokorelasi Durbin Watson dengan rumus $\mathrm{du}<\mathrm{d}<4$-du sehingga diperoleh nilai $1,736<2,558<4-1,736=1,736<2,558<2,264$. du (Tabel) adalah 1,736 dilihat dari $d u K^{\prime}=3$ pada kolom $n=100$. Dengan demikian kedua variabel bebas dalam penelitian ini layak untuk dianalisis lebih lanjut.

4. Uji Heterokedastisitas

Situasi heterokedastisitas akan menyebabkan penaksiran koefisien-koefisien regresi menjadi tidak efisien dan hasil taksiran dapat menjadi kurang atau juga melebihi dari yang semestinya. Dengan demikian, agar koefisien-koefisien regresi tidak menyesatkan maka situasi heterokedastisitas harus dihilangkan dari model regresi. Salah satu cara untuk menguji heterokedastisitas ini adalah dengan melihat penyebaran dari varians residual dengan melihat Scatterplot. Dalam penelitian ini penyebaran varians residual terjadi pada gambar 2 : 


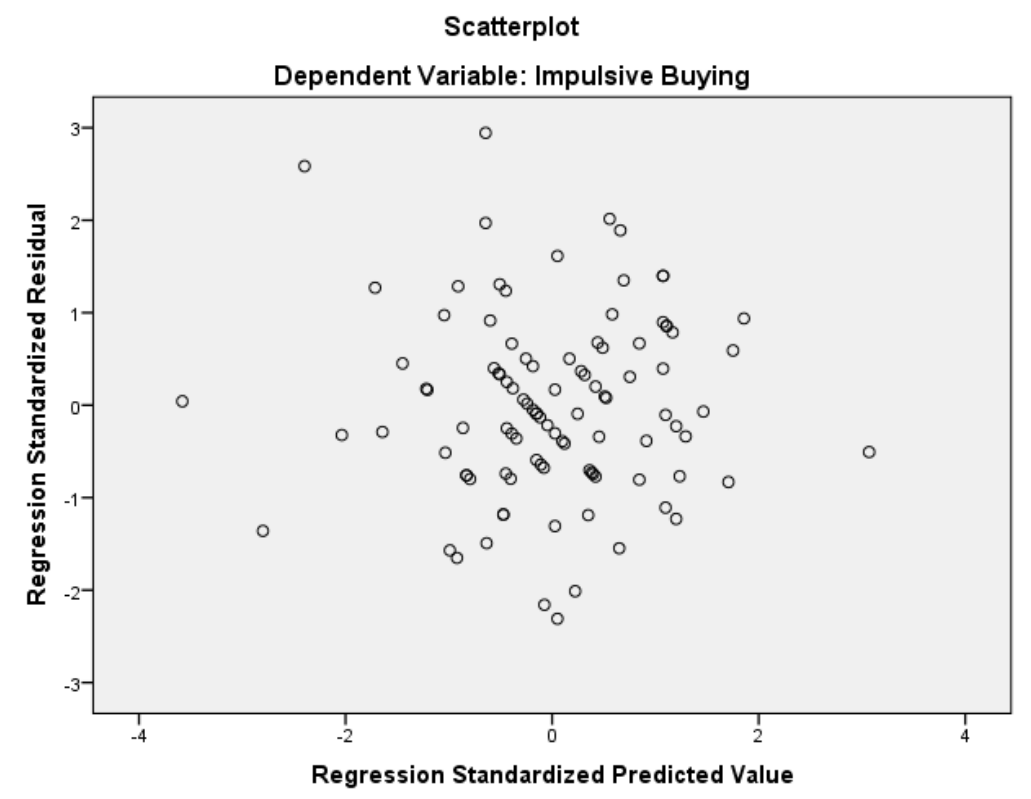

Gambar 2. Scatterplot

Gambar 2 menjelaskan bahwa penyebaran varians residual tidak membentuk pola tertentu. Ini berarti bahwa data yang diperoleh dalam penelitian layak untuk digunakan.

5. Uji Linieritas

Asumsi dalam uji linieritas menyatakan bahwa untuk setiap persamaan regresi linier hubungan antar variabek independen dan dependen harus linier. Untuk melihat linieritas dapat melihat grafik hubungan antara variabel hedonic shopping value $\left(\mathrm{X}_{1}\right)$, store atmosphere $\left(\mathrm{X}_{2}\right)$ terhadap impulsive buying (Y) pada konsumen Carrefour Pontianak pada gambar 3 :

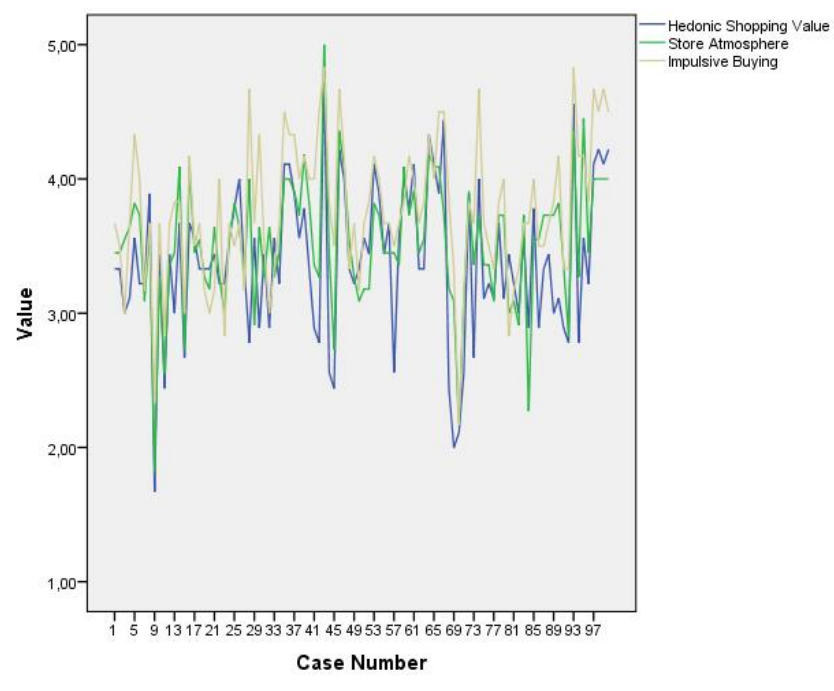

Gambar 3. Kurva pengaruh hedonic shopping value $\left(X_{1}\right)$, store atmosphere $\left(X_{2}\right)$ terhadap impulsive buying $(Y)$ pada konsumen Carrefour Pontianak 
Gambar 3 menjelaskan bahwa pergerakan kurva variabel hedonic shopping value dan store atmosphere terhadap terhadap impulsive buying adalah linier. Oleh karena itu data layak untuk dilakukasn uji regresi baik secara parsial maupun secara simultan.

d. Uji Analisis Regresi

1. Pengujian Hipotesis secara Parsial

Pengujian hipotesis secara parsial adalah untuk mengetahui faktor-faktor apa saja diantara variabel bebas yang paling dominan mempengaruhi kepuasan kerja. Untuk membuktikan hipotesis yang diajukan adalah benar maka dengan menggunakan software program SPSS V.20 dilakukan perhitungan regresi berganda. Hasil perhitungan terlihat pada tabel 4 :

Tabel 4 Hasil Analisis Regresi Berganda

\begin{tabular}{|c|c|c|c|c|c|c|c|}
\hline & \multirow[t]{2}{*}{ Model } & \multicolumn{2}{|c|}{$\begin{array}{c}\text { Unstandardized } \\
\text { Coefficients }\end{array}$} & \multirow{2}{*}{$\begin{array}{c}\text { Standardized } \\
\text { Coefficients }\end{array}$} & \multirow[t]{2}{*}{$\mathbf{T}$} & \multirow[t]{2}{*}{ Sig. } & \multirow[t]{2}{*}{ Korelasi Parsial } \\
\hline & & B & Std. Error & & & & \\
\hline \multirow[t]{3}{*}{1} & (Constant) & 0,792 & ,253 & & 3,134 & ,002 & \\
\hline & $\mathrm{X} 1$ &, 125 & ,091 & ,135 & 1,374 & , 173 & ,089 \\
\hline & $\mathrm{X} 2$ & ,722 &, 107 & ,663 & 6,750 &, 000 & ,438 \\
\hline
\end{tabular}

Dari hasil perhitungan yang ditunjukkan diperoleh persamaan regresi sebagai berikut :

$$
Y=0,792+0,125 X_{1}+0,722 X_{2}+e
$$

Berdasarkan persamaan regresi dan tabel output uji t, pengaruh variabel hedonic shopping value $\left(\mathrm{X}_{1}\right)$ terhadap impulsive buying $(\mathrm{Y})$ dapat dilihat pada Tabel 5 :

Tabel 5 Pengaruh hedonic shopping value terhadap impulsive buying

\begin{tabular}{|c|c|c|c|}
\hline$\beta$ & $\mathbf{t}_{\text {hitung }}$ & $\mathbf{t}_{\text {tabel }}$ & Korelasi P arsial \\
\hline 0,792 & 3,134 & 1,67 & 0,138 \\
\hline
\end{tabular}

Berdasarkan tabel 5 diambil kesimpulan mengenai hedonic shopping value terhadap impulsive buying adalah sebagai berikut :

a. Nilai $t_{\text {hitung }}$ lebih besar dari $\mathrm{t}_{\text {tabel }}$ untuk $\alpha=0,05 \%$ dan derajat bebas $=95$ sebesar 1,67, sehingga dapat diambil keputusan menolak $\mathrm{H}_{\mathrm{o}}$ dan menerima $\mathrm{H}_{\mathrm{a}}$, hal ini berarti berdasarkan hasil penelitian terdapat pengaruh yang signifikan dari variabel hedonic shopping value $\left(\mathrm{X}_{1}\right)$ terhadap impulsive buying $(\mathrm{Y})$. 
b. Sehingga jika nilai variabel hedonic shopping value $\left(\mathrm{X}_{1}\right)$ naik sebesar 1 satuan, maka nilai variabel impulsive buying (Y) akan meningkat pula sebesar 0,138 dengan asumsi variabel independen lainnya konstan.

c. Nilai korelasi parsial sebesar 0,138 menunjukkan keeratan hubungan hedonic shopping value $\left(\mathrm{X}_{1}\right)$ dengan impulsive buying $(\mathrm{Y})$. Diperoleh besarnya pengaruh parsial hedonic shopping value $\left(\mathrm{X}_{1}\right)$ dengan impulsive buying $(\mathrm{Y})$ adalah $(0,138)^{2} \times 100 \%=1,90 \%$.

Berdasarkan persamaan regresi dan tabel output uji t, pengaruh store atmosphere $\left(\mathrm{X}_{2}\right)$ terhadap impulsive buying (Y)dapat dilihat pada Tabel 6 berikut:

Tabel 6 Pengaruh store atmosphere terhadap impulsive buying

\begin{tabular}{|c|c|c|c|}
\hline$\beta$ & $\mathbf{t}_{\text {hitung }}$ & $\mathbf{t}_{\text {tabel }}$ & Korelasi Parsial \\
\hline 0,792 & 3,134 & 1,67 & 0,565 \\
\hline
\end{tabular}

Berdasarkan Tabel 6 dapat diambil beberapa kesimpulan sebagai berikut:

a. Nilai thitung lebih besar dari tabel untuk $\alpha=0,05 \%$ dan derajat bebas $=95$ sebesar 1,67 sehingga dapat diambil keputusan menolak $\mathrm{H}_{\mathrm{o}}$ dan menerima $\mathrm{H}_{\mathrm{a}}$, hal ini berarti berdasarkan hasil penelitian terdapat pengaruh yang signifikan dari store atmosphere $\left(\mathrm{X}_{2}\right)$ terhadap impulsive buying (Y)

b. Sehingga jika nilai variabel store atmosphere $\left(\mathrm{X}_{2}\right)$ naik sebesar 1 satuan, maka nilai variabel impulsive buying (Y) akan meningkat pula sebesar 0,565 dengan asumsi variabel independen lainnya konstan.

c. Nilai korelasi parsial sebesar 0,565 menunjukkan keeratan hubungan store atmosphere $\left(\mathrm{X}_{2}\right)$ dengan impulsive buying $(\mathrm{Y})$. Diperoleh besarnya store atmosphere $\left(\mathrm{X}_{2}\right)$ dengan impulsive buying $(\mathrm{Y})$ adalah $(0,565)^{2} \times 100 \%=31,92 \%$.

Jadi dari hasil penelitian ini dapat disimpulkan $1,90 \%$ terjadinya impulsive buying di Carrefour Pontianak pengaruhi oleh hedonic shopping value dan 31,92\% terjadinya impulsive buying pada Carrefour Pontianak dipengaruhi oleh store atmosphere.

2. Pengujian Hipotesis secara Simultan

Pengujian hipotesis ini berguna untuk mengetahui pengaruh yang signifikan secara bersamasama atau keseluruhan antara variabel bebas yang meliputi variabel hedonic shopping value $\left(\mathrm{X}_{1}\right)$ dan store atmosphere $\left(\mathrm{X}_{2}\right)$ terhadap impulsive buying $(\mathrm{Y})$. Dari perhitungan yang telah dilakukan, diperoleh hasil pengujian korelasi berganda secara simultan sebagai berikut: 
Tabel 7 Hasil Pengujian Korelasi Berganda

\begin{tabular}{|c|c|c|c|c|c|}
\hline $\begin{array}{c}\text { Dependent } \\
\text { Variable }\end{array}$ & $\begin{array}{c}\text { Independent } \\
\text { Variable }\end{array}$ & $\begin{array}{c}\text { Multiple } \\
\mathbf{R}\end{array}$ & F-hit & F-Tabel & Signifikasi \\
\hline $\mathrm{Y}$ & $\mathrm{X}_{1}, \mathrm{X}_{2}$ & 0,592 & 70,287 & 1,53 & $0,000^{\mathrm{a}}$ \\
\hline
\end{tabular}

Berdasarkan Tabel 7 F-hitung sebesar 70,287 dan F-tabel pada taraf nyata $\alpha=0,05$ sebesar 1,53 Oleh karena F-hitung lebih besar dari F-tabel, atau dapat juga dilihat dari nilai probabilitas sebesar $0,000^{\mathrm{a}}$ yang berada di bawah $\alpha=0,05$, maka dapat disimpulkan bahwa Ho ditolak dan Ha diterima sehingga dapat diartikan bahwa variabel hedonic shopping value $\left(\mathrm{X}_{1}\right)$ dan store atmosphere $\left(\mathrm{X}_{2}\right)$ berbengaruh secara signifikan terhadap impulsive buying Carrefour Pontianak (Y).

Sedangkan besarnya pengaruh secara bersama-sama antara variabel hedonic shopping value $\left(\mathrm{X}_{1}\right)$ dan store atmosphere $\left(\mathrm{X}_{2}\right)$ berbengaruh secara signifikan terhadap impulsive buying pada Carrefour Pontianak (Y) ditunjukkan oleh nilai $\mathrm{R}^{2}$ sebesar 0,592. Artinya 59,2\% terjadinya impulsive buying dipengaruhi oleh hedonic shopping value $\left(\mathrm{X}_{1}\right)$ dan store atmosphere $\left(\mathrm{X}_{2}\right)$, sedangkan sisanya $40,8 \%$ merupakan pengaruh faktor lain yang tidak diteliti dalam penelitian ini.

\section{KESIMPULAN}

Pada penelitian mengenai pengaruh hedonic shopping value dan store atmosphere terhadap impulsive buying pada konsumen Carrefour di Pontianak dapat ditarik kesimpulan bahwa hedonic shopping value dan store atmosphere berpengaruh secara signifikan terhadap impulsive buying konsumen carrefour Pontianak sehingga dua variabel tersebut dapat dijadikan sebagai kriteria penting yang mampu untuk mempengaruhi konsumen dalam melakukan aktifitas belanja. Segala hal yang berhubungan dengan atribut produk dan kondisi toko pada saat berbelanja menjadi hal yang penting dalam keputusan pembelian. Berdasarkan perhitungan yang telah dilakukan sesuai dengan kaidah dan standarisasi pengukuran uji pengaruh dikertahui bahwa store atmosphere memiliki pengaruh yang lebih besar yaitu sebesar 31,92\% terhadap impulsive buying disbanding hedonic shopping value hedonic shopping value yang berdasarkan perhitungan hanya memiliki nilai pnegaruh sebesar $1,90 \%$. Hal tersebut didasarkan pada tingkat kenyamanan konsumen pada saat melakukan proses belanja sehingga menjadikan kondisi toko mendapat persentase yang lebih besar dibandingkan dengan faktor lain. Berdasarkan seluruh perhitungan yang telah dilakukan dapat disimpulkan bahwa kondisi toko memiliki daya tarik tersendiri bagi konsumen untuk melakukan aktifitas belanja.

\section{SARAN}

Saran yang berkenaan dengan penelitian ini bagi manajemen Carrefour Pontianak untuk dapat meningkatkan impulsive buying konsumen agar memperhatikan lebih lanjut mengenai store atmosphere karena berdasarkan penelitian yang telah dilakukan bagian ini merupakan bagian yang paling menarik bagi konsumen untuk lebih attention, interest, desire and action dalam melakukan transaksi belanja. Pihak manajemen diharapkan dapat lebih menyusun serapi mungkin produk dan 
ornament penunjang yang terpajang disetiap bagian gondola. Saran lain adalah diharapkan pihak manajemen memberikan pelatihan secara intensif terhadap staf agar memiliki kemampuan yang lebih dalam memberikan perhatian dan tanggapan yang baik kepada konsumen dalam proses transaksi sehingga setiap konsumen merasa nyaman dan aman. Proses hedonic shopping value dapat terjadi jika promo terhadap produk tertentu dilakukan sesuai dengan kebutuhan konsumen. Seperti di akhir dan awal bulan yang menjadi puncak transaksi diharapkan pihak manajemen memberikan diskon potongan harga yang cukup menarik.

\section{DAFTAR PUSTAKA}

[1] Veronica, Rachmawati., 2009, Hubungan Antara Hedonic Shopping Value, Positive Emotion dan Perilaku Impulsive Buying Pada Konsumen Ritel. Majalah Ekonomi Vol. 19, No. 2, hal 192-209.

[2] Silvera D.H. Lavack. A.M And Kropp, F. 2008, Impulsive Buying The Role Of Affect, Social Influence and Subjective Wellbeing, Journal Of Consumer Marketing, Vol. 25, No.1, hal 23-33.

[3] Gilber, David, 2003, Retail Marketing Management, Second Edition, Prentice Hall.

[4] Lizamary, Angelina., Edwin, Japarianto. 2014,. Analisa Pengaruh Hedonic Shopping Value Terhadap Impulsive Buying Dengan Shopping Lifestyle dan Positive Emotion Sebagai Variabel Intervening Pada Mall Ciputra World Surabaya. Jurnal Manajemen Pemasaran Vol. 8 No. 2 Hal. 80-89

[5] Wingdes, Irawan, 2016, Pengaruh Karakteristik Pengguna Sosial Media Terhadap Keputusan Pembelian (Studi Kasus di Pontianak). Jurnal Sistem Informasi dan Teknologi Informasi, Vol. 5, No. 1 , hal. 50-60

[6] Windiarto, Gilang. 2014, Pengaruh Hedonic Shopping Value terhadap Impulsive Buying di Mediasi oleh Positive Emotion pada Konsumen Carrefour Plaza ambarukmo Yogyakarta. Jurnal Manajemen dan bisnis, Vol. 10 No. 1a. Hal 1-8

[7] Laksono, Veronica Lavinia. 2013, Pengaruh Shop Environment, Staff. Integrated Marketing Communication dan Hedonic Value terhadap Impulsive Buying Pada KOnsumen Carrefour di Surabaya, Kajian Ilmiah Mahasiswa Manajemen, Vol. 2, No. 4, Hal. 1-7

[8] Rusalty, Putria Rizky, 2013. Pengaruh Store Atmosphere Nannys Pavillion di Paific Place Terhadap Respon Emosional Konsumen. Jurnal Ilmiah Universitas Bakrie, Vol. 1, No.4

[9] Sugiyono, 2016. Statistik Untuk Penelitian, Cetakan Ke 27, Cv. Alfabeta, Bandung.

[10] http://www.dukcapil.kalbarprov.go.id/statistik Data Agregat Kependudukan Semester 2 Tahun 2016

[11] Sugiyono,2012, Metode Penelitian Bisnis, Cetakan ke 16, Cv 